\title{
Characterization and Identification of Diesel Fuels, Biodiesel and their Blends by Time-Resolved Laser- Induced Fluorescence Spectroscopy
}

\author{
Zhu Fan ${ }^{1}$, Jürgen Krahl \\ ${ }^{1}$ Technologietransferzentrum Automotive der Hochschule Coburg (TAC), Friedrich-Streib-Straße 2 \\ D-96450 Coburg (Germany), \\ zhu.fan@hs-coburg.de
}

\begin{abstract}
:
A method based on time-resolved laser-induced fluorescence spectroscopy (TRLFS) for characterization and identification of different fossil diesel fuels, biodiesel and theirs blends is introduced. The method uses a pulsed Nd:YAG laser with an excitation at $266 \mathrm{~nm}$ and a single nanosecond pulse, measuring the dynamic response with a specific time gate width and gate step (time-resolved), and comparing them in terms of 3D-shapes, frequency behavior and decay behavior. The method also takes into account the maximal intensities and the wavelength of the maximal fluorescence intensity. With this information it is possible to differentiate quickly diesel fuels and is as well useful for in-situ-detection of the biogenic content in biodiesel blends.
\end{abstract}

Key words: TRLFS, fossil diesel fuel, biodiesel, frequency behavior, decay behavior.

\section{Introduction}

Methods based on fluorescence spectroscopy are easy to use and deliver fast and accurate results $[2,3,4,5,6,7,8,9,10]$. However, these methods are challenging in remote sensing application, because this requires the use of tunable lasers which usually have too weak intensities [11, 12].

A method of time-resolved laser-induced fluorescence spectroscopy is suitable for remote sensing applications using an intense Q-switched laser. It was applied for the identification of fossil fuel $[13,14]$.

In contrast to long measurement times of GC/MS (about $1 \mathrm{~h}$ ) TRLFS-technique needs only two or three minutes and it provides the advantage of an online measurement application.

Aim of our work is to find fundamental spectroscopic dependencies to detect and distinguish conventional fuels, biogenic fuels and especially blends with different biogenic content. Based on that knowledge a spectroscopic fuel sensor may be developed that enables electronically the on-board optimization of combustions engines.

\section{Spectroscopic Methods and Materials}

Due to interference of the individual spectra of numerous fluorophores fluorescence in diesel fuels is complex. The compounds with a large conjugated double-bond system or benzene rings are major sources of fluorescence in diesel fuel. The absorption of light in the conjugated system excites a $\pi$ electron into an antibonding $\pi^{*}$ orbital ( $\pi-\pi^{*}$ transition). The fluorescence peaks of aromatic compounds are shifted to longer wavelengths (red shift) with increasing alkylation $[15,16]$.

For the time resolved measurements it has to be considered that the fluorescence emission can be described like monomolecular reactions, thus the temporal emission profile can be described by the simple exponential decay function $I_{F, t}$ with lifetime $\tau[17,18]$ :

$I_{F, t}=I_{F, t=0} \cdot e^{\left(-\frac{t}{\tau}\right)}$

Where $I_{F, t=0}$ is the intensity at $t=0$ and $\tau$ is the lifetime.

For a complex mixture of $\mathrm{N}$ fluorophores is the $\mathrm{I}_{F, t}$ the sum of fluorescent intensities of all fluorophores $\mathrm{i}$ : 
$I_{F_{i}, t}=\sum_{i=1}^{N} I_{F_{i}, t=0} \cdot e^{\left(-\frac{t}{\tau_{i}}\right)}$

The experimentally measured $l_{\text {exp.,t }}$ is a convolution of the instrument response function (excition pulse) $I_{\text {pulse,t }}$ and the decay function $I_{F, t}$.

The time resolved measurements can be used for the characterization and determination of analytes and for the separation of overlaying and interfering signals because their lifetimes are different from each other.

The TRLFS in this work is carried out by the pulse method (time domain) and harmonic. With short laser pulse (approx. 3 ns) the sample is excited, and the intensity of the emission versus time is recorded using a detector unit (spectrograph and an intensified chargecoupled device camera (ICCD-camera) with internal delay generator) with high temporal resolution. The experimental TRLFS-system OPTIMOS delivered by Optimare Wilhelmshaven, Germany is based on pulse method (time domain) and harmonic wavelength generation. The TRLFS is equipped with a pulsed Q-switched Nd:YAG pumped laser (Continuum, Minilite II) and a multi-channel detector ICCD camera (Andor IStar, A-DH72018U-03) in combination with spectrometer (Shamrock 163, A-SR-163) [19].

The emission spectra of different fluorophores were recorded in the range $200-600 \mathrm{~nm}$ with a specific time gate width (min. 2 ns) and gate step (min. $2 \mathrm{~ns}$ ), excited at $266 \mathrm{~nm}$.

The remote sensing experimental set up is shown in figure 1. All components of the OPTIMOS (laser, detector and delay generator) are integrated into an aluminum rack with operation panel. The device is covered by the aluminum housing.

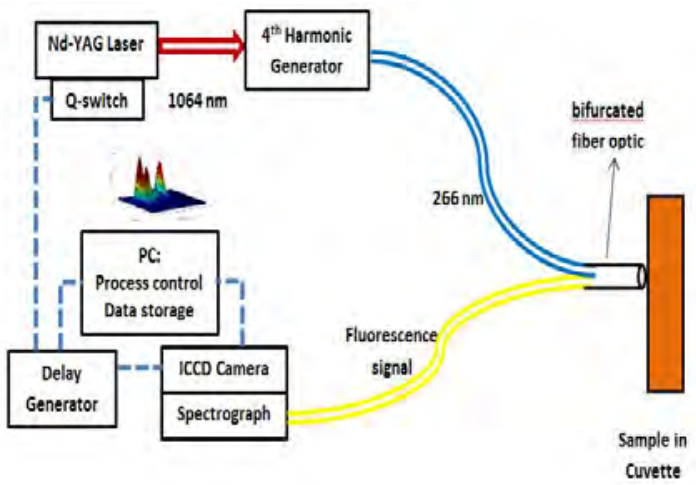

Fig. 1: Schematic diagram of remote sensing experimental set up of Optimos-System

The sensor head is connected to the device with ca. $5 \mathrm{~m}$ glass fiber and the sample is excited by UV-pulses $(266 \mathrm{~nm})$ from the fourth harmonic output of a Q- switch ND:YAG laser $(1064 \mathrm{~nm})$ via optical fiber. The laser-induced fluorescence signal is split by the spectrometer and detected by the multi-channel detector ICCD-camera. The bifurcated fiber optic comprises two optical fiber connected with laser and detector unit. These optical fibers are combined into one common fiber connected with the sensor head in a "Y"-type configuration.

When a measurement is started via software, a trigger signal is send from the PC-controller card to the internal delay generator of the ICCD-camera. From here a trigger is directly send to the flash lamp of the laser.

The ICCD-camera is opened with given delay after the initial trigger. The opening time of the ICCD-camera is described by the gate width parameter and is also given by the software. The gate width should be as short as possible in order to reduce the background signal. A temporal resolution is achieved by a stepwise temporal shift of the detection gate.

The TRLFS-measurement was performed on fuels in a quartz cell. Fluorescence was detected between 200 and $600 \mathrm{~nm}$.

\section{Fuels}

Most fuels were bought from filling stations or delivered by mineral oil or biofuel companies. We prepared modest volumes of different biodiesel blends ourselves. Additionally, the Thünen-Institute of Agricultural Technology (TI), Braunschweig, Germany, delivered different biodiesel qualities and blends of first and second generation biofuels.

\section{Results}

TRLFS allows identification and quantification of diesel fuel without sample preparation. Figure 2 showed 3D - TRLFS fluorescence spectra of nine different fuels (top, left to right: Aral diesel fuel (up to $7 \%$ biodesel), Aral Ultimate (biodiesel free), TI-Blend (blend of biodiesel, HVO, alcohol); middle: Swedish MK1 (aromatics free), CRC reference diesel fuel "DK9" by Haltermann (20\% aromatics), Hydrotreated Vegetable Oil (HVO); bottom: diesel from CNPC, South China, diesel from Argentina, Shell V Power).

These spectra represent fluorescence intensities as function of wavelength ( $\mathrm{x}$-axis) and decay time (y-axis). The observed discriminations that occur in the shapes of the TRLFS spectra were significant enough to be used for differentiation between diesel fuels and their blends with biodiesel. 

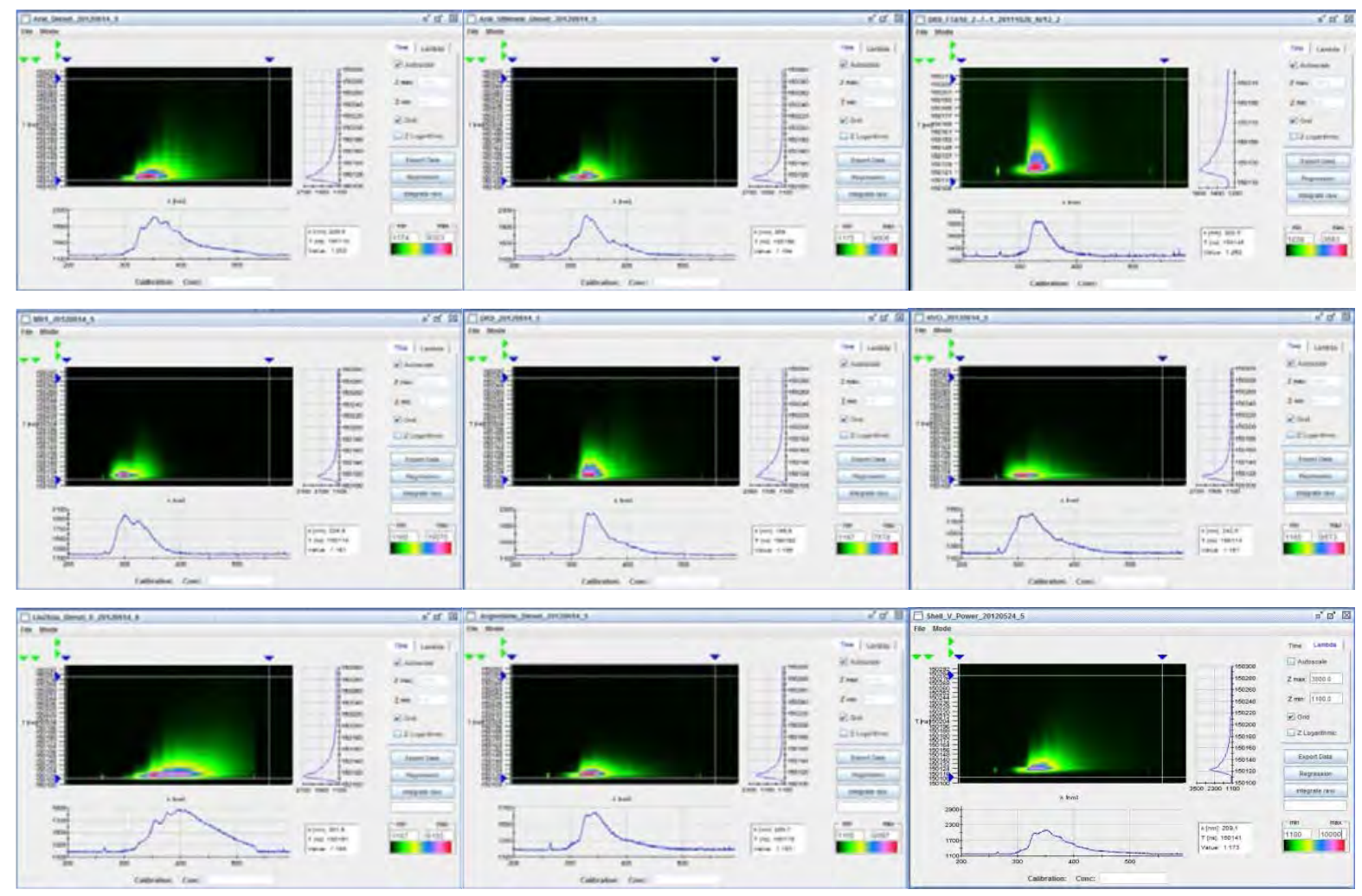

Fig. 2: 3D-TRLFS-fluorescence spectra profile of nine different fuels, excitation at $266 \mathrm{~nm}$
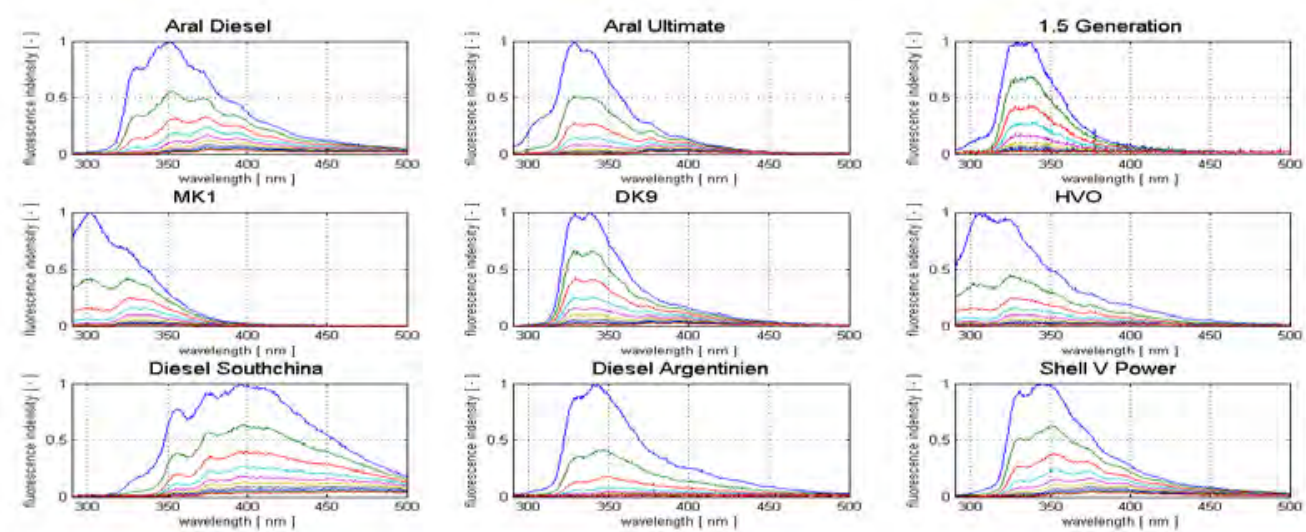

Fig. 3: Normalized time resolved fluorescence spectra for 10 time slices of nine different fuels, excitation at 266 $\mathrm{nm}$

In order to study and compare the time resolved fluorescence properties of diesel fuel its normalized fluorescence spectra could be used as the standard spectra of the diesel fuel. The normalized-fluorescence spectra were obtained by dividing the fluorescence by theirs maximal intensity. In order to reduce data in the time-axis the time domain would be separated into 10 time slices of $10 \mathrm{~ns}$. Within each time slice the fluorescence was integrated over the period at each wavelength. Such integrated frequency behavior could clearer illustrate the time resolved fluorescence property of diesel fuel.
The normalized time resolved fluorescence property for nine diesel fuels are shown in figure 3.

With the sub-divide of the time slice the differentiation of diesel fuels come clearer. The fluorescence spectra for all fuels are different as a result of the fluorophores composition and concentration. Also decay behaviors at different wavelengths are significant different from each other. Therefore fluorophores with different lifetimes can be distinguished. Based on this 
information the separation of overlapping fluorescence spectra is possible.

To characterize and identify the diesel fuels and biodiesel blends the fluorescence lifetimes for characteristic wavelengths were calculated. The lifetimes at characteristic wavelengths of different fuels are listed in the table 1.

Under the conditions, which include analyte at low concentration in homogeneous solution with negligible matrix interference under constant experimental conditions (temperature, pressure ...), a simple relationship between fluorescence intensity and analyte concentration $B X$ is given by
Fluorescence Intensity $=k \cdot B X / \%+b$

Do determine the biodiesel content in diesel fuel a lot of blends were prepared from reference diesel fuel (DK9) and rapeseed oil methyl ester (RME). Figure 4 shows that the fluorescence intensity for the emission at the wavelength of $335 \mathrm{~nm}$ decreases almost linearly with the increase of biodiesel concentration up to $90 \%$. For raw biodiesel the fluorescence is much lower than expected. The possible reasons are too large differences of emission efficiency between biodiesel and fossil diesel fuel or secondary absorption of fluorescence by the compound in biodiesel blends.

Tab. 1: Lifetimes of the nine fuels at the characteristic emission wavelengths

\begin{tabular}{|c|c|c|c|c|c|c|c|c|c|}
\hline $\begin{array}{c}\text { Lifetimes wavelength } \\
\text { [ns 1 }\end{array}$ & $\begin{array}{c}300 \\
\mathrm{~nm}\end{array}$ & $\begin{array}{c}328 \\
\mathrm{~nm}\end{array}$ & $\begin{array}{c}335 \\
\mathrm{~nm}\end{array}$ & $\begin{array}{c}356 \\
\mathrm{~nm}\end{array}$ & $\begin{array}{c}377 \\
\mathrm{~nm}\end{array}$ & $\begin{array}{c}396 \\
\mathrm{~nm}\end{array}$ & $\begin{array}{c}407 \\
\mathrm{~nm}\end{array}$ & $\begin{array}{c}414 \\
\mathrm{~nm}\end{array}$ & $\begin{array}{c}423 \\
\mathrm{~nm}\end{array}$ \\
\hline Fuels & 15 & 12 & - & 19 & 29 & 37 & 36 & 39 & - \\
\hline Aral Diesel & 7 & 16 & 16 & - & 35 & 57 & 58 & 69 & - \\
\hline Aral Ultimate & 14 & 24 & 24 & 28 & 40 & 64 & 53 & 76 & - \\
\hline 1.5 Generation & 11 & 21 & - & - & 33 & 40 & 39 & 48 & 55 \\
\hline MK1 & - & 23 & 22 & - & 37 & 54 & 47 & 48 & - \\
\hline DK9 & 12 & 16 & 19 & - & 22 & 22 & 21 & 22 & - \\
\hline HVO & - & 9 & 9 & 15 & 21 & 22 & 22 & 22 & 24 \\
\hline Diesel South China & 14 & 11 & 11 & - & 16 & 17 & 16 & - & 18 \\
\hline Diesel Argentina & 14 & 14 & 15 & 22 & 34 & 44 & - & 45 & - \\
\hline Shell V-Power & & & & & & & & \\
\hline
\end{tabular}

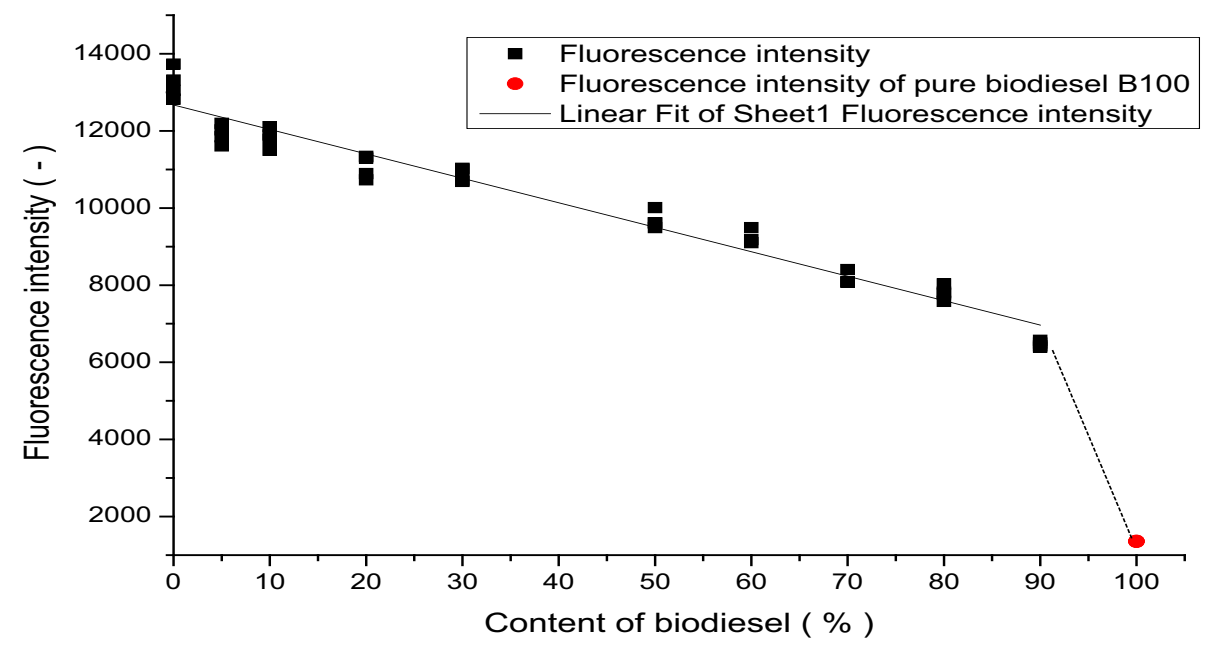

Fig. 4: fluorescence intensity for emission at wavelength $355 \mathrm{~nm}$ versus biodiesel content in fuel blends 


\section{Conclusion}

Different fuels could be characterized and identified by TRLFS without sample preparation. The method is much faster than GC/MS, can easily differentiate diesel fuels of diverse origin and determine the biodiesel content in fuels.

Until now almost 50 different diesel fuels were measured and the results are saved as a data base. In future, this data base should be enlarged by more diesel fuels from Europe, Asian and North/South America.

\section{Acknowledgements}

This work has been financially supported by Fachagentur Nachwachsende Rohstoffe e.V. (FNR), "Fluoreszenzspektroskopische Charakterisierung und Identifizierung von Kraftstoffgemischen zur Entwicklung eines Kraftstoffsensors (TRLFS) - Project 22004710." We thank the Thünen-Institut of Agricultural Technology for their support and the supply of biofuel blends.

\section{References}

[1] A. Munack and J. Krahl: Erkennung des RME-Betriebes mittels eines BiodieselKraftstoffsensors, Landbauforschung Völkenrode, 257 Special Issue (2003)

[2] T. Hengstermnn and R. Reuter, Lidar fluorosensing of mineral oil spills on the sea surface, Applied Optics. 29(22), 32183327 (1980)

[3] R. Barbini, R. Fantoni, A. Palucci, S. Ribezzo and H.J.L. van der Steen, Spectral and time resolved measurements of pollutants on water surface by a XeCL laser fluorosensor, Advances in Remote Sensing. 1(2), 46-51 (1992)

[4] P. Camagni, A. Colombo, C. Koechler, N. Omenetto, P. Qi and G. Rossi, Fluorescence response of mineral oils: spectral yield vs absorption and decay Time, Applied Optics. 30(1), 26-35 (1991)

[5] S. Patsayeva, V. Yuzhakov, V. Varlamov, R. Barbini, R. Fantoni, C. Frassanito and A. Palucci, Laser Spectroscopy of Mineral Oils on Water Surface, EARSeL eProceedings. 1, 106-115 (2000)

[6] J. Steffens, E. Landulfo, L.C. Courrol and R. Guardani, Application of Fluorescence to the Study of Crude Petroleum, J Fluoresc 21, 859-864 (2011); doi: $10.1007 / \mathrm{s} 10895-009-0586-4$

[7] M.D. Scherer, S.L. Oliveira, S.M. Lima, L.H. Andrade and A.R. Caires, Determination of the Biodiesel Content in Diesel/Biodiesel Blends: A Method Based on Fluorescence Spectroscopy,
Fluoresc., 1027-1031 (2011); doi: 10.1007/s10895-010-0815-x

[8] C.Y. Ralston, X. Wu, O.C. Mullins, Quantum Yields of Crude Oils, Appl Spectrosc 50, 1563-1568 (1996)

[9] B.M. Kulkarni, B.G. Pujar and S. Shanmukhappa, Investigation of acid oil as a source of biodiesel, Indian J Chem Technol 15, 467-471 (2008)

[10] A. Zawadzki, D.S. Shrestha and B. He, Biodiesel Blend Level Detection using Ultraviolet Absorption Spectra, Trans ASABE 50(4), 1349-1353 (2007)

[11] M.F. Quinn, A.S. Alotaibi, P.S. Sethi, F. Albahrani and O. Alameddine, Measurement and Analysis Procedures for Remote Identification of Oil Spills Using a Laser Fluorosensor, J Int Rem Sen 15, 2637-2658 (1994)

[12] A.G. Ryder, T.J. Glynn, M. Feely and A.J. Barwise, Characterization of Crude Oils Using Fluorescence Lifetime Data, Spectrochimica Acta A 58, 1025-1038 (2002)

[13] E. Hegazi, A. Hamdan and J. Mastromarino, Remote Fingerprinting of Crude Oil using Timeresolved Fluorescence Spectra, Arabian J for Science and Engineering 30, 1-12 (2005)

[14] I. Jacob, J. Krahl and H. Gnuschke: Einsatz der zeitaufgelösten Laserfluoreszenz-spektroskopie bei der Analyse partikelgebundener PAK. Abschlussbericht aus der Hochschule Coburg, 67 S. 2006.

[15] I. Dumke and M. Teschner, Application of fluorescence spectroscopy to geochemical correlation problems, Organic Geochemistry 13, 1067-1072 (1988)

[16] G.K. Khorasani, Novel development in fluorescencemicroscopy of complex organic mixtures: Application in petroleumgeochemistry, Organic Geochemistry 11, 157-168 (1987)

[17] R.A. Lampert, L.A.Chewter, D. Phillips, D. V. O'Connor and A.J. Roberts, Standards for nanosecond fluorescence decay time measurements, Anal. Chem. 55, 68-73 (1983)

[18] J.R. Lakowicz, I. Cryczynski, G. Laczko and D. Gloyna, Picosescond fluorescence lifetime standards for frequency- and timedomain fluorescence, J. Fluorescence 1, 87-93 (1991)

[19] Optimos \& Optimos-Midi Opreration Manual, Optimare $\mathrm{GmbH}$ (2005) 